\title{
Investigating the User Behavior of Peer-to-Peer File Sharing Software
}

\author{
Shun-Po Chiu (Corresponding author) \\ $\mathrm{PhD}$ candidate, Department of Information Management \\ National Central University, Jhongli, Taoyuan, Taiwan \\ $\&$ \\ Lecture, Department of Information Management \\ Vanung University, Jhongli, Taoyuan, Taiwan \\ E-mail: spchiou@gmail.com \\ Huey-Wen Chou \\ Professor, Department of Information Management \\ National Central University, Jhongli, Taoyuan, Taiwan \\ E-mail: hwc928@gmail.com
}

Received: March 26, 2011

Accepted: May 10, 2011

doi:10.5539/ijbm.v6n9p68

\begin{abstract}
In recent years, peer-to-peer file sharing has been a hotly debated topic in the fields of computer science, the music industry, and the movie industry. The purpose of this research was to examine the user behavior of peer-to-peer file-sharing software. A methodology of naturalistic inquiry that involved qualitative interviews was used to collect data from 21 university students in Taiwan.

The results of the study revealed that a substantial amount of P2P file-sharing software is available to users. The main reasons for using P2P file-sharing software are to save money, save time, and to access files that are no longer available in stores. A majority of respondents use P2P file-sharing software to download music, movies, and software, and the respondents generally perceive the use of such software as neither illegal nor unethical. Furthermore, most users are free-riders, which means that they do not contribute files to the sharing process.
\end{abstract}

Keywords: Peer to peer, File sharing, Naturalistic inquiry

\section{Introduction}

In recent years, Peer-to-Peer (P2P) network transmission technology has matured. Unlike the traditional manner of resource sharing, which was based on Client-Server architecture, when resources are exchanged in the P2P environment, each computer can act as both a server and a client simultaneously. In addition, current P2P file-sharing software is designed to support file downloads from multiple users. Therefore, the more people who download, the faster the process. This feature has made P2P software a popular tool of data exchange in a network since its launch. However, although P2P file-sharing software is becoming more useful, P2P technology is constantly misused. Network users transfer music, movie, software, and other proprietary data, which results in heavy financial losses to various industries. This situation has led many industries to engage in legal proceedings against suppliers of P2P file-sharing software. For instance, the former Napster became famous for providing the sharable MP3 files to Internet users, which led to a music copyright infringement lawsuit that shut down the site. However, as the saying goes, "while the priest climbs a foot, the devil climbs ten." Professionals in science and technology have continued to research and develop new peer-to-peer software technology. These professionals use legal platforms to break through the limitations of existing copyright law, which results in increasingly severe and intractable infringement.

Although considerable controversy exists concerning intellectual property rights and the use of P2P file-sharing software, P2P undeniably remains an important transmission technology in the history of Internet development. Therefore, it is worthwhile to explore the relevant behavior associated with the use of this technology. The purpose of this study is to investigate the motivations and behaviors that are associated with the use of P2P file-sharing software. 


\section{Literature Review}

Peer-to-peer technology has developed beyond a simple Client-Server architecture such that an independent peer node can simultaneously play multiple roles. Currently, there are two main applications of such technology: peer-to-peer file sharing and distributed computing. Peer-to-Peer file sharing allows users to play the role of a "client" who can directly access the files from other computers on the network. A user can also act as a "server" who shares files from his own computer with other users on the network. Because this software is powerful and free to use, it is increasingly popular on the Internet. In addition, some small offices that only have notebook or desktop computers use P2P file-sharing software to replace a dedicated file server. This use is known as "Distributed Computing" or "Grid Computing," names that refer to a technology that combines multiple computers to solve a single problem. Each user can share his unused CPU resources, resulting in a combined super computer to handle complex computing problems. At any given time, large enterprises typically have many computers in standby mode. Thus, P2P technology can be applied and the CPU resources can be used together.

Currently, scant research has been published on the user behavior of P2P file-sharing software. Asvanund et al. (2004) investigated the use of P2P file-sharing software in music sharing by gathering data from six OpenNap network users (OpenNap uses the same transmission mechanism as Napster, but it is completely independent from the Napster network). The results of this study indicated that as more people used the P2P file-sharing software and as network size increased, each user's contribution to the network showed a decreasing trend and the relative cost to the network showed an increasing trend. In other words, with an increasing number of users of the P2P file-sharing software, users were more reluctant to share files. The authors proposed that there is an optimal network size for P2P file-sharing software users, which is calculated as the point at which the marginal cost of a new user is close to but does not exceed his value.

In addition, Sandulli (2007) explored the factors that affect P2P music download activity with a survey of 4060 users from Spain who used P2P to download music. According to his research results, the factors of price, assortment, discovery, community, and download of music using P2P are negatively proportional to the purchase of music CDs. This means that, when the price of a music CD is expensive, when there are more options to download music online, when music is easy to search for, and when downloading is popular in a community, users tend to use P2P to download music.

Some studies of the Net Community have related to file sharing among users of P2P file-sharing software. Some scholars have discussed the motivation to participate in the net community to share knowledge or information. The results showed that the main motivating factors are altruism and reciprocity. (Constant et al., 1996; Wasko \& Faraj, 2000). In addition, Butler (2001) proposed a resource-based model of net community interaction with a Listserv net community as the study subject. The results showed the advantages and disadvantages of a large net community. The advantage is that when a community is larger, it provides more potential interaction; the disadvantage to a large community is that there are fewer opportunities to form personal relationships and each individual's contribution to file sharing will be smaller.

Unlike previous research, this study investigated the user behavior of P2P file-sharing software using the naturalistic inquiry method, which creates thick description that will provide readers with a better understanding of the user behavior of P2P file-sharing software.

\section{Methodology}

In this study, the naturalistic inquiry approach proposed by Lincoln and Guba (1985) was employed. Naturalistic inquiry is a qualitative method. The most important difference between qualitative and quantitative research is that they are based in different worldviews from different scientific paradigms. Quantitative research was developed under the paradigm of "positivism," which believes that a "unique and objective" truth exists and that the world is composed of stable and unchanging facts. Qualitative research is derived from the paradigm of "naturalism," which believes that the world is constructed through people's subjective experiences, and therefore phenomena are diverse and dependent on the definition of the individual and the collective environment. The naturalistic inquiry approach is mainly based on the following five assumptions:

1) Ontology: the assumption of ontology states that the real world is a unified whole, but that it is diverse and complex. In this study, people's motivations and behaviors related to P2P file-sharing software are discussed, and P2P file-sharing constitutes a diverse and complex structure.

2) Interaction between researchers and observers: the assumption of interaction between researchers and observers states that researchers and observers are not independent and disconnected. Naturalistic inquiry posits that this relationship involves continuous interaction and that the two roles are not separable in the course the research. In this study, interaction was carried out with the respondents through in-depth interviews and the behavior of the respondents was observed in the interaction. The process of continuous interaction between both sides was thus achieved.

3) Generalization: the assumption of generalization states that the results and findings of a study can only be applied in a specific time and context. The situation of $\mathrm{P} 2 \mathrm{P}$ file-sharing software use investigated in 
this study only represents the facts within the context and at the time of the study.

4) Causal inference: the assumption of causal inference states that it is unreasonable to emphasize a separation between cause and effect as would be done under traditional causality. The naturalistic research method assumes that cause and effect are interrelated, which means that cause and effect occur simultaneously. There is no way to distinguish between cause and effect. This study did not attempt to predict or explain a causal relationship between variables but simply investigated the use of P2P file-sharing software.

5) Value neutrality: the assumption of value neutrality states that research is influenced by the subjective consciousness of the researchers and the implied values in the field.

Using naturalistic inquiry method with thick description, researchers can interpret the world constructed by the informants and reconstruct that world for the readers. The readers can then judge the transferability of the findings by relating them to their own context (Guba \& Lincoln, 1985).

This research used the strategy of purposive sampling with a goal of maximizing variation within the sample. In-depth interviews were conducted with users of P2P file-sharing software. The interviews occurred between February 2010 and March 2010. The interview subjects were college students in the department of information management at a local university in Taiwan. These subjects were chosen because students majoring in information management were considered more familiar with computers and the Internet than students from other departments. After a brief description of the purpose of the interview, the students who agreed to participate were asked to sign the Interview Consent form (Appendix 1). The interview began after the form was signed. The interviews utilized open-ended questions, and the interview guide was revised as the interviews progressed (Appendix 2). After each interview, the researcher evaluated the richness of the information provided by the informant, the informant's attitude toward cooperation, and the saturation of the data to decide whether to conduct additional interviews. Written field notes were used to record the interview data. After interviewing 21 students and comparing the interview data, it was found that saturation had been reached, which means no new information was generated. At that point, the interview process was completed, and no new interviews were conducted. The demographic variables of respondents and the uses of P2P file-sharing software are summarized in the following table (Table 1). The respondents had between one and ten years of experience with P2P software, and all respondents used it at least once a week, with a maximum of more than 11 times per week.

To analyze the data, a constant comparative method of content analysis was applied (Glaser \& Strauss, 1967). In this study, the content of interview was first converted into a verbatim transcript (Transcription). Then, various smallest meaningful units of analysis were established according to the data (Units) to form the basic concepts of the analysis. These concepts were then classified (Categories), named (Naming) and coded (Coding) according to their attributes and characteristics (Properties). The module categories and their properties were continuously integrated (Integrating), condensed, consolidated and organized into subjects (Theme).

To increase the credibility of the study, this study used multiple data sources in a process of triangulation (Denzin, 1978). The data were reviewed with the participants (Member Checking), and the final report was made available to the respondents. In addition, the researchers used rich and detailed description to interpret the feeling and experience of the respondents and the world they constructed. This description is designed to allow readers to judge the transferability of the findings. The researchers also wrote a $\log$ (Reflective Journal). In different stages of the study, by writing in the reflective journal, researchers reflected on the personal and subjective dimensions of the research methods, the field observations, the findings of study, and other topics.

\section{Results}

A total of 355 coding cards were created in the data analysis. The codes are shown in Table 2 according to their classification by topic. The topics mainly cover the adoption of use, type of software, feature of software, value of software, file sharing, legal awareness, future development, and suggestions.

\subsection{Software Adoption}

The respondents mentioned that they initially came into contact with P2P file-sharing software mainly through reports on such software in newspapers, magazines, and online forums. After this initial contact, the respondents started to pay attention to P2P file-sharing software. Some people were interested in this software because they saw their classmates or friends using it; some people came into contact with P2P file-sharing software because the teacher introduced it in class. The following are some answers provided by respondents to the question of how they came into contact with P2P software:

After reading about the software in a computer magazine, I became aware that such useful software existed, and then searched for it on the Internet by myself. (II)

I found it because it was discussed in a forum. (I2)

I noticed that there was a lot of hacked software on the laptop of another student in the classroom. Upon inquiry, I found out that he downloaded them from the Internet using P2P file-sharing software. (I5)

A classmate of mine always had the latest movies and she told me that they were downloaded from the 
Internet. She also said that many people were using it and encouraged me to use it too. (I6)

After I occasionally saw a friend using it and asked him about it, I became aware of such software. My friends recommended it to me. He also taught me how to install the software and download the mp3s shared by others on the network. (I11)

When I was in the e-commerce course, my teacher introduced it, which is how I knew there was such useful software. (I14)

Fishbein and Ajzen (1975) indicated that users of an information system may be influenced by support and encouragement from people with whom they have important relationships, such as colleagues, friends, or supervisors and other. According to the interviews in this study, the reason some respondents are indeed influenced to use P2P file-sharing software by significant others, as in the case of the teacher's introduction and or the cases where friends and classmates encouraged P2P use. In addition, the study also found that media coverage and online forum discussions also had an impact on the respondents.

\subsection{Type of software}

According to the interview data, the P2P file-sharing software used by the respondents included three major types: BitTorrent, eDonkey/eMule and FOXY. Among these, eMule was developed based on eDonkey and they share similar features, so this study will group them as one type. BitTorrent has the support of various software including Azureus, BitComet, BitLord, BitSpirit, utorrent and others. These software applications share a common characteristic; that is, they are all free to use. They were voluntarily developed by a group of programmers and then placed on a website as a free download. The updated versions of the software and related service resources were continuously provided. The followings are the some respondents' answers concerning the use of P2P file-sharing software:

I mainly use Azureus, which is a BT download tool. (I1)

BT has a lot of supporting software. I used to use BitLord. Later, someone introduced utorrent to me. Now I have switched to utorrent. (I2)

I use eMule and BitComet. Each of these two types of P2P software has its own strength. eMule has a convenient searching function, which allows direct download of the resulting files after searching with the keywords input directly; BT BitComet belongs to the class of BT. A "seed" provided in a place like a forum is first required to download the necessary files. (I8)

$I$ am using more than one kind of P2P file-sharing software. I use FOXY to search songs, and utorrent or eMule to look for software and movies. (I9)

In particular, almost all respondents simultaneously used more than one type of P2P file-sharing software. Usually, eMule or eDonkey was used to search for less popular or very old files and records; BitTorrent was used to download currently popular movies or the latest software; and FOXY was used to download music.

\subsection{Features of the Software}

Different kinds of software have different operating mechanisms. For example, eMule/eDonkey and FOXY employ the function of directory sharing. As long as users place the files for sharing into the directory, they are available for people to download. These two types of software have the function of file searching, which allows users to input keywords to conduct a search. Once the desired file is found, it can be downloaded directly with a click. BitTorrent employs the function of seed sharing. In addition to providing the file for sharing, the donating user also needs to establish a corresponding seed file as a shared media, which contains the relevant information of the sharing file. Usually, the seed file is placed on the message boards or forums by the provider. After getting the seed, the corresponding file can be downloaded by clicking on the seed. In general, the download speed of eMule is slower than that of BitTorrent. For those who just started using eMule, the amount of data uploaded might be more than of the amount that is downloaded, but over time, the downloading results tend to improve. These are the opinions of the respondents about the features of different types of P2P file-sharing software:

File sharing in BT usually has a relatively complete graphic introduction, which is not available in eMule. (I4)

About 2-3 weeks after it is posted, the BT seed is usually lost and disconnected. In fact, eMule has a similar situation, which may cause a stall in the download and the download is unable to be completed. (I5)

If only partial information (such as artist name, album name) is known for the file to download, it can be searched and downloaded through eMule and FOXY. (I9)

Downloading with BT seems like concentrating our firepower on one seed, so it is often faster than eMule. But the seed usually has a lifetime. Once it is no longer popular, the file may not be available to download. (I13)

BT download has a time constraint of about a month or so. Because most BT players usually close the file for sharing shortly after the files needed have been downloaded. (I15) 
For eDonkey, as long as the software is running, the movie or software downloaded earlier is automatically sharable. The file sharing cannot be forced to close. So some older software can often be found with eDonkey/eMule. (I17)

However, the BitTorrent seed file is not readily available. It often requires visiting several sites to find the desired seeds. In addition, forums set a limit for seed downloads such that users who do not reach a certain membership level are not allowed to download. To upgrade one's membership level, a user needs to provide new resources to others. That is, the more files one provides to share, the higher level he/she reaches. Some forums use virtual coins to trade. The individual who provides the file can set the required number of coins for the download, and those who want to download the seed have to pay that number of coins.

A few years ago, when BT was just starting to be used, the seeds were fairly easy to download. Later, forums successively designed some restriction mechanisms so that many seeds were not available for users of the lower membership level to download. (I6)

I joined many forums as a member in order to obtain the desired seeds. For example, when a forum did not allow me to download the seed due to insufficient membership level, I could sometimes download it at other sites. (I10)

When downloading, the downloaded file may sometimes be false. Therefore, before downloading, it is better to read the related articles on the forum and note others' responses. However, there is sometimes no way to determine whether the file has problems because the seed is too new. Further, some users may experience early closure for the file, which causes part of the download to be missing. These are some respondents' comments regarding false or incomplete downloads:

Sometimes I have encountered the case of incomplete download, which is usually caused by the closing of file sharing by the provider. (I15)

Sometimes I have downloaded a false file, which is really infuriating, especially when downloading large files. (I17)

I used to read the articles posted in the forum by the people who had finished downloading. After I made sure it was the right one, I started to download. (I20)

As mentioned earlier, the respondents used three types of P2P file-sharing software: BitTorrent, eDonkey/eMule and FOXY. These three types each have their own modes of operation and features. The respondents determined which type of file sharing software to use according to their needs. Table 3 shows the general characteristics of the P2P file-sharing software used by the respondents.

4.4 Value of Software

P2P file-sharing software can be considered as a file platform. It is mainly used for file transfers and allows users to exchange with each other; the file donors provide the files for sharing, and the file acceptors can access the files. According to the interviews, the main types of files that were downloaded were movies, television programs, cartoons, comics, music, software packages, software programs, and documents. The value of using P2P file-sharing software is that it allows users to save money, to save time, to obtain old files that are no longer easily available in the market, to watch a movie preemptively, to download a software trial, to listen to the latest music, and other similar uses. Thus, P2P file-sharing software has considerable benefits to attract users. The related interview content from some respondents is presented here:

I can download the desired software, movies, music, etc. It is very easy to use. (I1)

Without paying the price, I can obtain the desired files. For example, the latest movies that have not even been released yet in Taiwan are available on the Internet. Although sometimes the image quality is not very good and there is some noise, what more can we ask if it is free? (I2)

After spending a little time looking for the seeds, the download can be executed as long as the computer is on. Although the cost of electricity increases, this small expense is really nothing compared to the price of the software. (I3)

I can download TV series such as: cartoons, Japanese TV dramas or Korean TV dramas, which I really love to watch. The most important thing is that it is free. (I8)

I do not need to spend time to make a purchase, and I do not need to spend money either. (I19)

P2P file-sharing software is really handy. For me, it is like a spiritual food. (I20)

As a result of digitization, music, videos, images, books, magazines, software, and other such items can all be converted into file formats. Therefore, P2P file-sharing software allows users to find many different types of files. According to the view of value, so-called value refers to the advantages provided by an item (quality and benefit) minus the overall effort required to obtain it (cost and expense) (Zeng \& Rao, 2010). The customer perceived value is the value judgment regarding a certain product made by a customer who calculated what he/she can get for what he/she pays. In terms of P2P file-sharing software, the costs to the users include time, effort, electricity, Internet fees, and the depreciation of computer network equipment; what they obtain includes the quality and 
benefits of the downloaded files. In other words, P2P file-sharing software allows users to reduce their expenditure, including the effort, energy, time, and money spent on the file purchase. For users who download copyrighted files (such as software, movies, music, magazines, and books), monetary savings might be the biggest motivation for them to use P2P file-sharing software.

\subsection{File Sharing}

Although P2P file-sharing file software is a file sharing platform and users download and upload simultaneously, the interviews indicate most users are mainly engaged in downloading activity. In view of this, P2P file-sharing software is designed to force a certain ratio of upload and download. For downloading-only users who do not provide shared files, at least some of their bandwidth must be configured to share the files that they download. In addition, eDonkey/eMule and FOXY require a personal shared directory in which files are made public and available to others to download. However, in establishing the shared directory, the user must be careful to avoid an outflow of personal information or important files. Compared to BT, eMule attaches more importance to the concept of uploading and sharing. When a user begins to use eMule, uploading activity may be greater than downloading activity. Over time, downloading activity should improve. If an eMule user wants to download without restrictions, his upload speed must be higher than 10KB. Additionally, eMule has a scoring system that allows users who upload files to share to achieve better results in terms of downloading. Hence, some people try to improve their scores by running eMule at all times. As the respondents said:

I do not know how to make seed files. Of course, I have never uploaded a file before. (II)

When I am downloading, I am also sharing. When the download is complete, I would remove the seed and stop sharing. (I3)

I never play the role of providing files, only sharing while downloading. (I4)

I do not share. After I finish downloading, I move the file to another directory. (I10)

Why are we so stingy? I always leave some files in the directory to share. (I15)

My eMule is always running even nothing is being downloaded. To keep it on is just to do a favor to others and to accumulate the score from unknown users. When it becomes my time to download files, the speed will be fast. (I17)

According to interview data, in the world of P2P file-sharing software, it seems that more people accept files than donate them. However, P2P file-sharing software has two sharing mechanisms. The first is "user voluntary share," which means that users are free to set file sharing; the other is the "system forced share." Under this approach, the system forces users to share the files that they are currently downloading using the P2P file-sharing software. The users are also forced to open a certain percentage of bandwidth to upload shared files. As scholars of knowledge sharing have pointed out, users who use the first mechanism to share may be motivated by altruism and reciprocity (Constant et al., 1996; Wasko \& Faraj, 2000). With the second mechanism, users have no choice but to share, regardless of whether they have an attitude of altruism and reciprocity. In addition to avoiding the predicament of having no users who are willing to share, the main purpose of this mechanism is to increase all users' download speed because the more users who share at one time, the faster the download speed for each user.

\subsection{Legal Awareness}

Using the exchange platform, users download, reproduce and provide files to other members to download, upload and exchange files. Whether this behavior is legally authorized is a topic of debate for the copyright industry and for P2P software operators. Users' awareness of legal norms is similarly ambiguous. Based on our interview results, some respondents were aware that their download behavior infringed upon copyright or intellectual property law and should be punished. However, others believed that they downloaded files for personal use with no commercial activity, so the activity was not illegal and they had no fear of being caught. These are some of the responses concerning the interviewees' legal awareness:

I know that it violates copyright law. But I will still use it because it is really handy. (II)

It seems illegal, but I am not so sure. (I3)

Everybody is using it. It should not be illegal, right? (I4)

I am not so worried about being arrested. I think the probability is lower than winning the lottery. (I5)

It is unlikely to be caught, because thousands of people or even more in Taiwan alone are using P2P software every day. It will be an endless job to catch them. I do not think anyone is so bored to catch these players. (I7)

I know it is illegal. But I should not be caught as such a small role. I just downloaded. (I13)

As long as we do not download or upload copyrighted software, it should be nothing to worry about. (I14)

It is for my personal use only. It should not be illegal! (I16)

However, a few years ago, two domestic companies that provide P2P file-sharing software, Kuro and ezpeer, 
were indicted by prosecutors. These companies have since changed their business model to legal downloading for a fee. At that time, FOXY took advantage of the opportunity to replace these companies and became the most popular free download software; FOXY is now the third P2P file-sharing software company to appear in court. The software designer was sentenced recently in the Court of First Instance of Taiwan (www.chinatimes.com, 2010). It was found that FOXY provided a platform for users with mandatory sharing function by default, which constituted a violation element of the element of "public transport" in the Copyright Law (Ministry of Economic Affairs, Intellectual Property Office, Taiwan, 2010).

In addition, users of $\mathrm{P} 2 \mathrm{P}$ file-sharing software infringe on copyrights through the uploading and downloading the copyrighted files. In accordance with the provisions of the Copyright Law of Taiwan, all behaviors of uploading, downloading, posting, transferring and storage of online articles, pictures, music, videos and other works using P2P file-sharing software are acts of reproduction. All acts of reproduction without consent violate the "reproduction right" and the "public transmission rights" of copyright holders. Even though the respondents knew that downloading copyrighted files was illegal and carried a risk of being caught, the interview respondents persisted in downloading. This is because the respondents in this study were college students with no income or little income. Copyrighted software may have been too expensive for them to afford, so they preferred to take the legal risks.

\subsection{Future Development}

Regarding the future of P2P file-sharing software, most respondents were optimistic. All respondents agreed that P2P technology could be continually improved as more people used the technology. Regarding for the infringement of copyright law, the respondents believed that there will be further developments in the future. After some operators of P2P file-sharing software lost copyright infringement cases in court, the respondents worried that such cases could limit the development of $\mathrm{P} 2 \mathrm{P}$ by reducing innovation from the technology sector.

I have been able to successfully download the desired files without any problems. In the future, it should be still the same. (I5)

Although some eMule servers were forced to close, new servers will take their place. There is nothing to worry about. (I9)

Some P2P file-sharing software has been updated continually. I think it will continue to develop in the future. (II1)

Since some P2P file-sharing software businesses were prosecuted, I am really worried that such a good technology will disappear due to prohibition. (I15)

Both at home and abroad, P2P file-sharing software is beginning to be controlled. Everyone is going after it, more or less! (I16)

After seeing that FOXY was guilty in court, I feel that P2P is dying. (I18)

Indeed, the fact that some operators of P2P file-sharing software lost copyright infringement cases may have a negative impact on the development of P2P. However, we must understand that P2P technology itself is not illegal. The true violation is the inappropriate behavior of the users or operators, which has nothing to do with the technology. Although the Internet advocated freedom of innovation, people should be careful not to infringe the rights of others while encouraging innovation freedom on Internet.

\subsection{Suggestions}

In terms of suggestions for modifications that could be made to the software, the respondents indicated that they would like the software to have a more user-friendly configuration. Because the configuration parameters of some software are numerous and complex, even though one can use the software without knowledge of the technology, when transmission problems occur, the user often does not know how to address the problem. In addition, the download and upload speeds affect the network bandwidth. If the network is not adjusted to be optimal, the data flow will occupy the bandwidth of the entire network. Other computers in the same network will be affected, resulting in no Internet access. Some respondents wanted the software to provide more training on the software setup, which would enable the users to understand the relevant important settings. These are the respondents' suggestions:

After installation, the software can be used. But I don't understand the settings and did not change them at all. I hope the software can be simplified. (I6)

I had never been able to search files using eMule and I did not know what the problem was. Later I read an article in the forum and found that the problem was in Serverlist. It was restored after the Server list was fixed. How could I know that such a problem was occurring? I had also spent a long time trying to solve it. It is really a bit complicated. (I12)

When I first used it, I did not know it accounted for so much bandwidth, which caused some complaints from others. After spending a long time searching for a solution, I tried to reduce the number of bits per second for downloading and uploading and it worked. Therefore, I hope that software developers can provide simple 
training for basic setting to save the users from experiencing problems. (I14)

I wish that software that could not be traced would be developed, so that we do not have to worry about being caught. (I19)

According to the Technology Acceptance Model (TAM) proposed by Davis (1989), perceived ease of use and perceived usefulness will affect the use of information systems. P2P file-sharing software, which provides considerable usefulness to users, needs to be strengthened in terms of the ease of use dimension, however. The respondents in this study were students in the department of information management, who all had some computer literacy. Even for these students, however, P2P file-sharing software was difficult to configure. It is believed that for other users with no information technology background, this software will be more difficult to use.

\section{Discussion and Implications}

\subsection{Summary of Results}

Our results showed that respondents were using P2P file-sharing software mainly due to the introduction and encouragement from: friends, classmates, teachers, online forums, or newspapers and magazines. Most of the respondents used more than one kind of free P2P file-sharing software, mainly because different types of files can be downloaded using different types of software. According to the software features, the software can be divided into three types: BitTorrent, eDonkey/eMule and FOXY. Regarding software value, the respondents said that the main advantages of P2P file-sharing software are to save money, to save time, and to access the files that are difficult to obtain. In addition, the software allows users watch a movie preemptively, download a software trial, listen to the latest music, and other similar functions.

In file sharing, the respondents in this study mostly intended to download. Most people were forced to share and upload by the software only when downloading files. Only a few people maintained the connection and opened files for uploading when they were not downloading. One reason that the respondents did not want to take the initiative to share files, is that they were afraid of being traced as a source of copyright infringement. Regarding legal awareness, there were considerable differences among the respondents. Some respondents believed that their behavior was illegal, while others thought it was not illegal and that the law was unclear. For respondents who downloaded copyrighted files even though they knew it was illegal, they probably did so because they were college students with little discretionary income. Thus, they could not afford the purchase price of the files they wanted, which led them to download illegally.

\subsection{Implications for Theory and Practice}

Although P2P technology has been developed for a long time and with many users, little qualitative research has examined relevant user behavior related to P2P software. This study is the first to use the naturalistic inquiry method to explore the user behavior of P2P software. Compared to traditional empirical research, it has the advantage of providing a more extensive description of the user behavior of $\mathrm{P} 2 \mathrm{P}$ file-sharing software (Belk et al. 1988)

In addition, for users of P2P software, it is recommended that they should engage in illegal behavior. Everyone should understand that "there is no free lunch." All of the files on the network, except those that are described as allowed legal downloads (for example, open source code, shareware, and movie trailers), have owners and should not be downloaded at will. In addition, before using P2P software, users must first understand the related software configuration software to avoid inadvertently sharing computer that are files not meant to be shared, which could cause serious consequences.

Although Taiwan's copyright law clearly states that the behavior of uploading or downing copyrighted files using P2P software violates "the right of reproduction" and "the right of public transmission," some respondents in this study still believed that the behavior of downloading copyrighted files was not illegal. It is therefore evident that a large gap exists between public awareness and copyright laws. Thus, we suggest that government agencies should strengthen public awareness of copyright law. More education on legal information should be provided in schools.

Currently, many business groups whose copyrights have been infringed upon have taken legal action against the illegal operators of P2P file-sharing software. However, it is indisputable that P2P file-sharing transmission platforms perform a powerful function that attracts users. Businesses may want to try a different tactic, to actively seek a business model that can take advantage of this innovative technology to add value to the enterprise and create market opportunity.

For designers and suppliers of P2P software, in addition to continuously developing better and faster software, new software designs should be easier to use to facilitate user adoption. Although some users have little knowledge about software settings, they can still use the software to complete file downloads. However, such users cannot address errors when they arise. Moreover, setting relevant parameters is directly relevant to the time of user file downloads and the network traffic throughout the region. Under a poor setting, the entire network could be disabled due to the exclusive occupation of bandwidth by downloads, which blocks other computers' 
Internet access. In addition, software vendors should to train users with detailed manuals.

The results of this study were presented in terms of the reality constructed by the researchers and the respondents. Future investigation can target users in different circumstances, and a different reality might be found as a result. The subjects of this study were college students. However, college students are not the only group of P2P users. To achieve a more detailed understanding of the user behavior of P2P file-sharing software, it is suggested that researchers investigate different population groups in the future.

In this study, a qualitative research method was applied to explore the user behavior of peer-to-peer file-sharing software. Quantitative analysis was not performed on the survey. Subsequent research could use quantitative research methods to conduct a more comprehensive investigation of the user behavior of peer-to-peer file-sharing software in future.

\subsection{Limitations}

In this study, in-depth interviews were utilized as the data collection method. However, the procedure of conducting interviews was time-consuming. It presented an additional burden to the respondents in terms of time spent on the study. The respondents may also have had problems incomplete memories, bias, and research issues; In addition, because the respondents might have concerns regarding their illegal behavior of downloading copyrighted files, they might be reluctant to give detailed answers. These factors may have affected the conclusions of this study, and have led to some errors that were difficult to avoid.

In addition, the sampling method used in this study is purposive sampling based on the approach of naturalistic inquiry. The respondents are students of the department of information management at a domestic university, so the results are limited to the reality constructed by the respondents and the researchers in this study.

\section{References}

Asvanund, A., Clay, K., Krishnan, R., and Smith, M. D. (2004). An empirical analysis of network externalities in peer-to-peer music-sharing networks. Information Systems Research, 15(2), 155-174. doi:10.1287/isre.1040.0020, http://dx.doi.org/10.1287/isre.1040.0020

Belk, R. W., Sherry, J. F., and Wallendorf, M. (1988). A naturalistic inquiry into buyer and seller behavior at a swap meet. Journal of Consumer Research, 14(4), 449-470. doi:10.1086/209128, http://dx.doi.org/10.1086/209128

Butler, B. S. (2001). Membership size, communication activity, and sustainability: a resource-based model of online social structures. Information Systems Research, 12(4), 346-365. doi:10.1287/isre.12.4.346.9703, http://dx.doi.org/10.1287/isre.12.4.346.9703

Constant, D., Sproull, L., and Kiesler, S. (1996). The kindness of strangers: the usefulness of electronic weak ties for technical advice. Organization Science, 7, 119-135. doi:10.1287/orsc.7.2.119, http://dx.doi.org/10.1287/orsc.7.2.119

Davis, F. D. (1989). Perceived usefulness, perceived ease of use, and user acceptance of information technology. MIS Quarterly, 13(3), 319-340. doi:10.2307/249008, http://dx.doi.org/10.2307/249008

Denzin, N. K. (1989). Interpretive Interactionism. New Bury Park, CA: Sage.

Fishbein, M., and Ajzen, I. (1975). Beliefs, Attitude, Intentions and Behavior: an Introduction to Theory and Research, Boston, MA: Addition Wesley.

Glaser, B. G., and Strauss, A. L. (1967). The Discovery of Grounded Theory: Strategies for Qualitative Research. Chicago: Aldine.

Guba, E. G., and Lincoln, Y. S. (1985). Naturalistic Inquiry. New Bury Park, CA: Sage.

Ministry of Economic Affairs, Intellectual Property Office. (2010). Copyright Law. [Online] Available: http://www.tipo.gov.tw/ch/AllInOne_Show.aspx?path=1362\&guid=a71977ea-6478-4e37-a46a-15497ba7c275\&1 ang=zh-tw. (February 10, 2010)

Sandulli, F. D. (2007). CD music purchase behaviour of P2P users. Technovation, 7, 325-334. doi:10.1016/j.technovation.2006.12.007, http://dx.doi.org/10.1016/j.technovation.2006.12.007

Wasko, M. M., and Faraj, S. (2000). Is it what one does: Why people participate and help others in electronic communities of practice? Journal of Strategic Information Systems, 9(2), 155-173. doi:10.1016/S0963-8687(00)00045-7, http://dx.doi.org/10.1016/S0963-8687(00)00045-7

www.chinatimes.com. (2010). FOXY software leader is facing to an astronomical claim. [Online] Available: http://showbiz.chinatimes.com/2009Cti/Channel/Showbiz/showbiz-news-cnt/0,5020,110511+112010032000042, 00.html. (March 20, 2010)

Zeng, G., and Rao, Y. (2010). Principles of Marketing. Taipei: Future Career Management Corporation. 
Table 1. Demographic variables

\begin{tabular}{|c|c|c|c|}
\hline \multicolumn{2}{|c|}{ Items } & Number & Percentage \\
\hline Gender & Male & 14 & 67 \\
Age & Female & 7 & 33 \\
& Under 20 (inclusive) & 6 & 29 \\
Experience using P2P & $21-30$ & 15 & 71 \\
file-sharing software & 1 year or less & 2 & 10 \\
Average weekly frequency of & $2-5$ years & 13 & 62 \\
P2P file-sharing software use & 6-10 years & 6 & 28 \\
& 1 time & 2 & 10 \\
& $2-5$ times & 7 & 33 \\
& $6-10$ times & 8 & 38 \\
\hline
\end{tabular}

Table 2. The number of cards with data on each topic from each interview respondent

\begin{tabular}{|c|c|c|c|c|c|c|c|c|c|}
\hline & $\begin{array}{l}\text { Software } \\
\text { adoption }\end{array}$ & $\begin{array}{l}\text { Type of } \\
\text { software }\end{array}$ & $\begin{array}{c}\text { Feature of } \\
\text { software }\end{array}$ & $\begin{array}{l}\text { Value of } \\
\text { software }\end{array}$ & $\begin{array}{c}\text { File } \\
\text { sharing }\end{array}$ & $\begin{array}{c}\text { Legal } \\
\text { awareness }\end{array}$ & $\begin{array}{c}\text { Future } \\
\text { development }\end{array}$ & Suggestions & Total \\
\hline $\mathrm{I} 1$ & 1 & 2 & 0 & 3 & 1 & 1 & 0 & 0 & 8 \\
\hline $\mathrm{I} 2$ & 1 & 3 & 0 & 5 & 1 & 1 & 0 & 0 & 11 \\
\hline $\mathrm{I} 3$ & 1 & 1 & 0 & 6 & 2 & 1 & 0 & 0 & 11 \\
\hline I4 & 1 & 2 & 2 & 5 & 2 & 1 & 0 & 0 & 13 \\
\hline I5 & 1 & 3 & 2 & 6 & 2 & 2 & 1 & 0 & 17 \\
\hline I6 & 1 & 2 & 3 & 6 & 2 & 1 & 1 & 1 & 17 \\
\hline I7 & 1 & 2 & 2 & 4 & 1 & 2 & 1 & 1 & 14 \\
\hline I8 & 1 & 3 & 3 & 4 & 1 & 1 & 1 & 0 & 14 \\
\hline I9 & 1 & 3 & 3 & 7 & 2 & 2 & 1 & 1 & 20 \\
\hline $\mathrm{I} 10$ & 1 & 2 & 2 & 6 & 2 & 2 & 1 & 1 & 17 \\
\hline I11 & 1 & 3 & 3 & 8 & 2 & 1 & 1 & 0 & 19 \\
\hline $\mathrm{I} 12$ & 1 & 3 & 3 & 9 & 2 & 2 & 1 & 1 & 22 \\
\hline $\mathrm{I} 13$ & 1 & 2 & 2 & 6 & 1 & 2 & 1 & 1 & 16 \\
\hline I14 & 1 & 2 & 2 & 4 & 1 & 2 & 1 & 1 & 14 \\
\hline I15 & 1 & 3 & 3 & 6 & 2 & 1 & 1 & 0 & 17 \\
\hline I16 & 1 & 2 & 2 & 7 & 2 & 2 & 1 & 1 & 18 \\
\hline I17 & 1 & 3 & 3 & 6 & 3 & 1 & 1 & 1 & 19 \\
\hline $\mathrm{I} 18$ & 1 & 3 & 3 & 6 & 2 & 2 & 1 & 0 & 18 \\
\hline I19 & 1 & 2 & 2 & 8 & 2 & 1 & 1 & 1 & 18 \\
\hline I20 & 1 & 2 & 3 & 6 & 2 & 2 & 1 & 0 & 17 \\
\hline $\mathrm{I} 21$ & 1 & 2 & 2 & 6 & 1 & 2 & 1 & 0 & 15 \\
\hline Total & 21 & 50 & 45 & 124 & 36 & 32 & 17 & 10 & 335 \\
\hline
\end{tabular}

Note: I refers to the respondent; the number in the table represents the number of cards. 
Table 3. The features of eDonkey/eMule, BitTorrent, and FOXY software

\begin{tabular}{|c|c|c|c|}
\hline & BitTorrent & eDonkey/eMule & FOXY \\
\hline Type of file & $\begin{array}{l}\text { Software, movies, music, and } \\
\text { others }\end{array}$ & $\begin{array}{l}\text { Software, movies, } \\
\text { music, and others }\end{array}$ & Mainly mp3-based music \\
\hline Age of file & $\begin{array}{l}\text { Shorter file lifetime, most are } \\
\text { new files, seeds will disappear } \\
\text { over time }\end{array}$ & $\begin{array}{l}\text { Longer lifetime, old } \\
\text { file can also be found }\end{array}$ & $\begin{array}{l}\text { Longer lifetime, old file } \\
\text { can also be found }\end{array}$ \\
\hline Search function & $\begin{array}{l}\text { No search function } \\
\text { Search needs to run on a forum }\end{array}$ & Yes & Yes \\
\hline Information on file & $\begin{array}{l}\text { The post with the seed on a } \\
\text { forum usually has a screenshot } \\
\text { and description }\end{array}$ & No & No \\
\hline Download & $\begin{array}{l}\text { A seed file needs to be } \\
\text { downloaded first }\end{array}$ & $\begin{array}{l}\text { Download directly } \\
\text { after searching }\end{array}$ & $\begin{array}{l}\text { Download directly after } \\
\text { searching }\end{array}$ \\
\hline Speed of download & Relatively fast & Relatively slow & Relatively slow \\
\hline
\end{tabular}

\section{Appendix 1: Interview Consent Form}

Research Topic: The user behavior of peer-to-peer file-sharing software

I consent to participate as a respondent in research on the user behavior of peer-to-peer file-sharing software. I will be shown in anonymous form wherever I am involved in the study. All of my interview data will be properly stored in a safe place, and only the researcher himself/herself has the right to access and read these data.

I have the right to read and question the reporting documents based on my interview data. I can withdraw from the study at any time without consent, and withdrawal will not have any negative impact on me.

I agree to allow the researcher to use my interview data to attend meetings and to publish papers.

I have read and understand the above statement and voluntarily agree to participate in this study.

Signature of respondent:

Date:

\section{Appendix 2: Interview Outline}

1. May I ask, under what circumstances did you first come into contact with P2P file-sharing software?

2. What kinds of P2P file-sharing software do you use? Why?

3. What are the reasons you use P2P file-sharing software?

4. What types of files do you download? What are the uses of your downloaded files?

5. How do you find information related to P2P file sharing?

6. In addition to downloading, did you share files? Please describe your experience of sharing.

7. Do you think the behavior of using P2P file-sharing software is illegal? As far as you know, what laws it may violate? Are you afraid of being caught?

8. According to your experience, what are the changes in the current P2P file-sharing software on the Internet compared to earlier software? What is your opinion for the future prospects of P2P?

9. Finally, do you have any suggestions for P2P file-sharing software? 